\title{
Association of Activating KIR Copy Number Variation of NK Cells with Containment of SIV Replication in Rhesus Monkeys
}

\author{
Ina Hellmann ${ }^{1}$, So-Yon Lim ${ }^{1}$, Rebecca S. Gelman ${ }^{2}$, Norman L. Letvin ${ }^{1 *}$ \\ 1 Division of Viral Pathogenesis, Beth Israel Deaconess Medical Center, Harvard Medical School, Boston, Massachusetts, United States of America, 2 Department of \\ Biostatistics, Dana Farber Cancer Institute and Harvard School of Public Health, Boston, Massachusetts, United States of America
}

\begin{abstract}
While the contribution of $\mathrm{CD}^{+}$cytotoxic T lymphocytes to early containment of HIV-1 spread is well established, a role for NK cells in controlling HIV-1 replication during primary infection has been uncertain. The highly polymorphic family of KIR molecules expressed on NK cells can inhibit or activate these effector cells and might therefore modulate their activity against HIV-1-infected cells. In the present study, we investigated copy number variation in KIR3DH loci encoding the only activating KIR receptor family in rhesus monkeys and its effect on simian immunodeficiency virus (SIV) replication during primary infection in rhesus monkeys. We observed an association between copy numbers of KIR3DH genes and control of SIV replication in Mamu- $A^{*} 01^{-}$rhesus monkeys that express restrictive TRIM5 alleles. These findings provide further evidence for an association between NK cells and the early containment of SIV replication, and underscore the potential importance of activating KIRs in stimulating NK cell responses to control SIV spread.
\end{abstract}

Citation: Hellmann I, Lim S-Y, Gelman RS, Letvin NL (2011) Association of Activating KIR Copy Number Variation of NK Cells with Containment of SIV Replication in Rhesus Monkeys. PLoS Pathog 7(12): e1002436. doi:10.1371/journal.ppat.1002436

Editor: Guido Silvestri, Emory University, United States of America

Received July 5, 2011; Accepted October 30, 2011; Published December 15, 2011

Copyright: (c) 2011 Hellmann et al. This is an open-access article distributed under the terms of the Creative Commons Attribution License, which permits unrestricted use, distribution, and reproduction in any medium, provided the original author and source are credited.

Funding: This work was supported by the NIAID Center for HIV/AIDS Vaccine Immunology grant AI067854. The funders had no role in study design, data collection and analysis, decision to publish, or preparation of the manuscript.

Competing Interests: The authors have declared that no competing interests exist.

* E-mail: nletvin@bidmc.harvard.edu

\section{Introduction}

Natural killer (NK) cells are the primary effector cells of the innate immune system, representing a first line of defense against viruses through their ability to lyse virally infected cells without prior antigen sensitization [1-3]. NK cells express a complicated set of activating and inhibitory receptors on their cell surfaces that recognize specific ligands on target cells [4]. Inhibitory receptors transmit inhibitory signals to NK cells that protect healthy cells from destruction by NK cell-mediated cytotoxicity, whereas activating NK cell receptors transmit activating signals to these effector cells. It is the balance of these opposing signals that determines the activation state of an NK cell and, in so doing, regulates NK cell-mediated killing and cytokine production [5-7]. Among these receptor families expressed by NK cells are the inhibitory and activating killer cell immunoglobulin-like receptors (KIR). The highly polymorphic KIRs recognize MHC class I molecules as ligands [8,9], and the coincident expression of certain KIRs and MHC class I molecules in an individual influences the outcome of a number of viral infections [10,11].

Recent studies have shown that activating KIRs and their MHC class I ligands can affect AIDS pathogenesis. The expression of KIR3DS1, an activating KIR receptor, has been shown to delay AIDS progression when its ligand, $H L A-B$ Bw 4 alleles with an isoleucine at position 80 (HLA-B Bw4-80Ile), is coexpressed in an individual [12]. Consistent with this finding, an in vitro functional analysis showed that KIR3DS1 ${ }^{+} \mathrm{NK}$ cells are able to inhibit HIV1 replication in HLA-B Bw4-80Ile ${ }^{+}$target cells [13]. Further, ${\mathrm{KIR} 3 \mathrm{DS} 1^{+}}^{+} \mathrm{NK}$ cells selectively expand during acute HIV-1 infection in the presence of HLA-B Bw4-80Ile [14]. In addition to these findings, others have reported an association between the expression of certain inhibitory KIR $3 D L 1$ allotypes and protection against HIV-1 disease progression, when the KIR3DLl ligand, $H L A-B$ Bw 4 alleles, is also expressed in an individual [15].

Studies of the contributions of NK cells to HIV-1 control have been limited by the difficulties associated with finding individuals who can be evaluated during the earliest phase of the infection. The SIV-infected rhesus monkey therefore provides a critical model for exploring NK cell biology in the setting of an AIDS virus infection [16]. We have previously shown that there are five KIR receptor families in rhesus monkeys [17]. KIR3DH is the only activating KIR family in this nonhuman primate species, and this family of molecules is highly polymorphic [18-21]. An understanding of this KIR gene family of rhesus monkeys provides an important basis for exploring the contributions of KIR receptors and NK cells in early AIDS pathogenesis in the SIV/macaque model. In the present study, we evaluated the copy number variation (CNV) of activating KIRs in rhesus monkeys and demonstrated an association between the extent of this CNV and SIV control during primary SIV infection in a cohort of $M a m u-A^{*} 01^{-}$rhesus monkeys that were homozygous for the restrictive TRIM5 alleles.

\section{Results}

Establishment and validation of a qPCR assay to determine KIR3DH CNV

This study was initiated to explore the copy number variation of activating KIR genes of Indian-origin rhesus monkeys and its 


\section{Author Summary}

NK cells are effector cells of the innate immune system that contribute to protection against virus infections through their ability to lyse virus-infected cells without prior antigen sensitization. Their role in controlling HIV-1 replication during primary infection has been uncertain. NK cell activation is regulated by inhibitory and activating KIRs that recognize MHC class I molecules expressed by target cells. In the present study, we identify an association between the copy number of activating KIR genes in rhesus monkeys and the control of SIV replication during primary infection in Mamu- $A^{*} 01^{-}$rhesus monkeys that express restrictive TRIM5 alleles. This observation underscores the potential importance of activated NK cells in the control of SIV spread during the early stages of infection.

contribution to the control of virus replication during the acute phase of SIV infection. To date, only one activating KIR receptor family, KIR3DH, also termed KIR3DS in recent publications to be consistent with the nomenclature used in describing human KIRs [19,21], has been identified in rhesus monkeys. Interestingly, the $K I R 3 D H$ receptor family in this macaque species comprises genes that display extensive polymorphism. To determine the copy number of activating KIR genes in rhesus monkeys, we developed a quantitative real-time PCR assay (qPCR) using a primer/probe set that binds to a conserved region of $K I R 3 D H$ genes that encodes the transmembrane domain of the KIR3DH proteins. This primer/probe set was designed to amplify 23 previously described KIR3DH alleles (GenBank accession numbers MmKIR3DH1-4 (AF334648-AF334651), MmKIR3DH7-21 (EU702453-EU702473), MmKIR3DH-like 1-4 (AY505479-82)) [17,18]. We confirmed that this primer/probe set does not bind inhibitory KIR genes by sequencing the qPCR amplicons (data not shown).

Genomic DNA derived from B-lymphoblastoid cell lines (B-LCLs) or peripheral blood mononuclear cells (PBMCs) of 77 rhesus monkeys was extracted, and KIR3DH copy numbers were determined for each monkey by qPCR using serial dilutions of a plasmid containing the amplicon of the $K I R 3 D H$ qPCR reaction. STAT6, since it is present at two copies per diploid genome (pdg), was used as a reference gene in these studies [22]. Intraexperimental reproducibility of the qPCR assay was confirmed by analyzing triplicate samples for each of the 77 monkeys in two separate experiments, determining KIR3DH copy numbers based on the means of the triplicate values $\left(R^{2}=0.866, \beta=0.816\right)$ (Figure 1A).

To validate the accuracy of the KIR3DH copy number qPCR assay, we developed a multiplex ligation-dependent probe amplification assay (MLPA). Twenty genomic DNA samples were analyzed using one oligonucleotide set for the KIR3DH genes and, for reference genes, two oligonucleotide sets for EP300 encoding the E1A binding protein p300 and one set for $C R E B B P$ encoding the CREB-binding protein. EP300 and CREBBP are each present at two copies pdg in the rhesus monkey genome. Because of the extensive polymorphism at the KIR3DH loci, only one MLPA oligonucleotide set could be designed that bound to the same KIR3DH genes amplified in the qPCR assay. Relative MLPA signals for $K I R 3 D H$, normalized against the control gene signals, were assessed in two MLPA experiments using the same DNA samples. These signals clustered into groups corresponding to copy numbers 2, 3, 4 and 5 (Figure 1B). The KIR3DH copy numbers determined by MLPA were correlated with KIR3DH

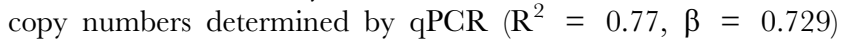
(Figure 1G).

\section{$K I R 3 D H$ copy numbers vary extensively in Indian-origin rhesus monkeys}

Using this assay, we determined $K I R 3 D H$ copy numbers in a cohort of 77 Indian-origin rhesus monkeys (Figure 2A). KIR3DH copy numbers varied extensively in this cohort of monkeys, ranging from 0 to 12 copies pdg (median $=4.11$ copies pdg). We rejected that this distribution had a Gaussian distribution by the skewness test $(P=0.001$; i.e., the distribution was not symmetric) as well as by the kurtosis test $(P=0.005$; i.e., the distribution is more sharply peaked than the Gaussian), the chi-squared test $(P=$ 0.0006), and the Shapiro-Wilks test $(P=0.003)$ (data not shown). Since the aim of this study was to determine the association of activating KIR copy numbers on early control of SIV replication, we first sought to determine whether activating KIR copy numbers in this species co-stratified with other alleles already implicated in SIV control. Therefore, we assessed whether KIR3DH copy numbers in this cohort of animals were associated with their $М а т и-A * 01$ or $М а т и-B^{*} 17$ status or their expression of particular TRIM5 alleles. The expression of certain MHC class I
A

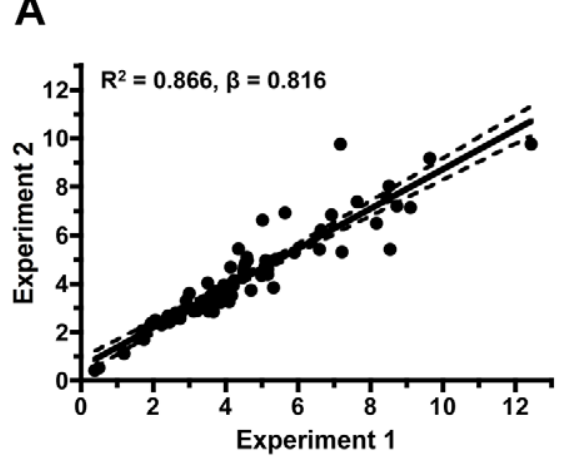

B

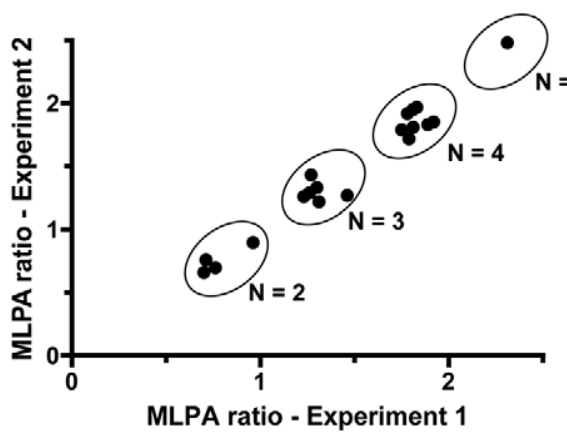

C

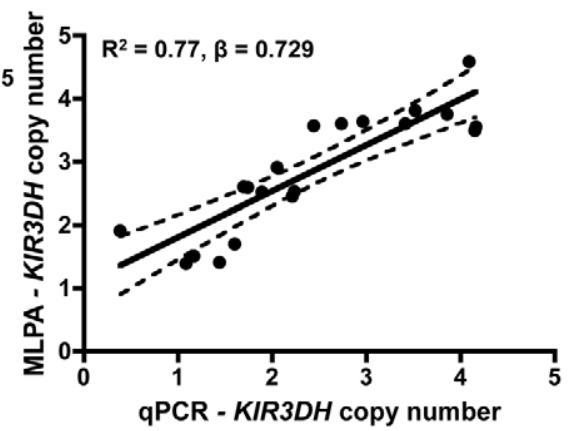

Figure 1. Intra-run reproducibility in $K I R 3 D H$ copy number determination and validation of quantitative real-time PCR estimates of $K I R 3 D H$ copy numbers by MLPA (multiplex ligation-dependent probe amplification). (A) $K I R 3 D H$ copy numbers were determined using triplicates of each DNA sample from 77 rhesus monkeys in two separate experiments to validate intra-experiment reproducibility $\left(R^{2}=0.87, \beta=\right.$ 0.816). (B) Comparison of signal ratios of two MLPA experiments. Pairs of ratios (20 samples) cluster around groups corresponding to KIR3DH copy numbers of 2, 3, 4 and 5. (C) Relationship between KIR3DH copy numbers determined by qPCR and MLPA ( $\left.\mathrm{R}^{2}=0.77, \beta=0.729\right)$. The $95 \%$ confidence interval is shown by dashed lines.

doi:10.1371/journal.ppat.1002436.g001 
A

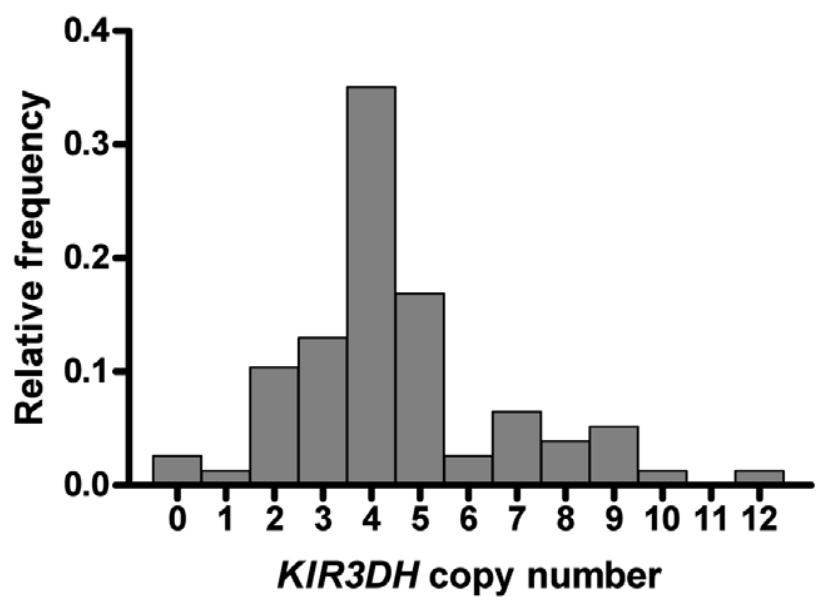

C

\begin{tabular}{lcccc} 
& $\mathbf{n}$ & Median & Mean & SD \\
\hline Combined & 77 & 4.111 & 4.498 & 2.194 \\
\hline $\mathrm{A}^{*} 01^{-}$ & 63 & 4.151 & 4.608 & 2.279 \\
$\mathrm{~A}^{*} 01^{+}$ & 14 & 3.737 & 4.005 & 1.748 \\
\hline $\mathrm{B}^{*} 17^{-}$ & 70 & 4.094 & 4.440 & 2.150 \\
$\mathrm{~B}^{*} 17^{+}$ & 7 & 4.490 & 5.084 & 2.710 \\
\hline TRIM5 6-11 & 37 & 4.127 & 4.355 & 1.907 \\
TRIM5 1-5 & 40 & 3.976 & 4.631 & 2.446 \\
\hline
\end{tabular}

B
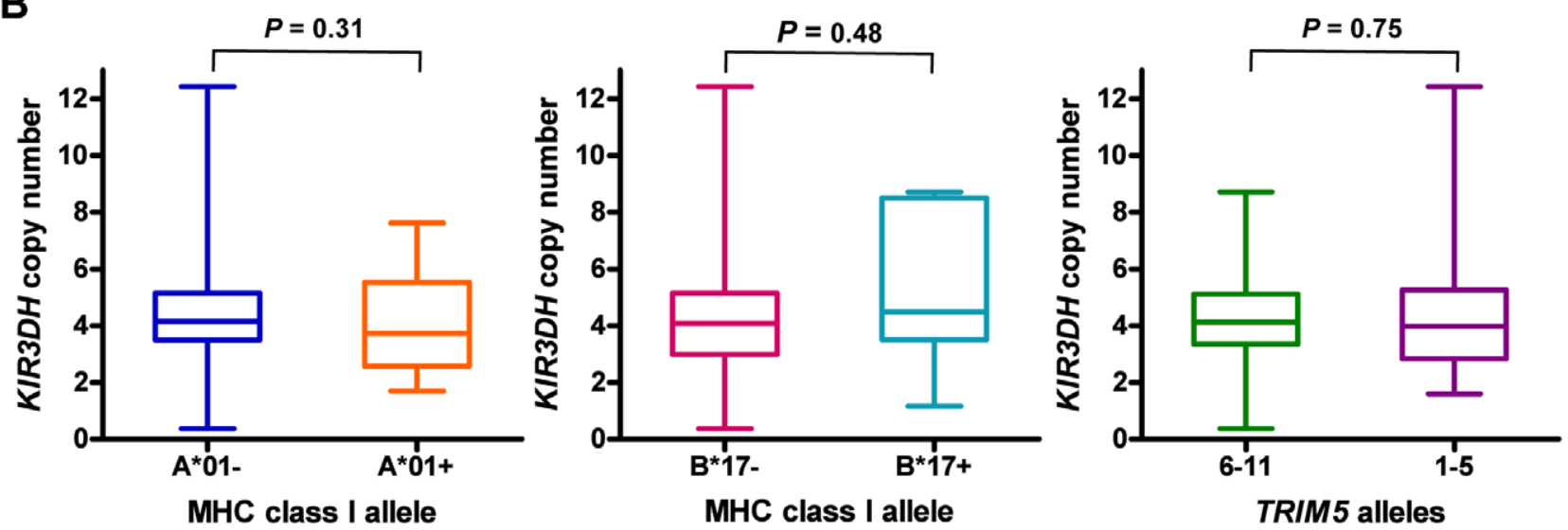

Figure 2. Distribution of $K I R 3 D H$ copy numbers in Indian-origin rhesus monkeys. Copy numbers of $K I R 3 D H$ genes were determined using quantitative real-time PCR on genomic DNA of 77 Indian-origin rhesus monkeys. (A) Distribution of KIR3DH copy numbers in the entire cohort of monkeys. (B) Boxplots of $K I R 3 D H$ copy number distribution in rhesus monkeys divided into three cohorts: $M a m u-A^{*} 01^{-}$and $M a m u-A^{*} 01^{+}$rhesus monkeys, Mamu- $B^{*} 1 T$ and Mamu- $B^{*} 17^{+}$rhesus monkeys and rhesus monkeys expressing only TRIM5 alleles $1-5$ or expressing at least one TRIM5 allele from the group 6-11. (C) The median, mean and standard deviation (SD) of KIR3DH copy numbers are shown for various subgroups of rhesus monkeys. $P$ values were calculated using the Mann-Whitney $\mathrm{U}$ test (two-tailed).

doi:10.1371/journal.ppat.1002436.g002

alleles, particularly Мати- $A^{*} 01$ and $М а т и-B * 17$, has been associated with control of virus replication and delayed disease progression following SIV infection of Indian-origin rhesus monkeys [23-27]. We have also recently demonstrated the role of rhesus monkey TRIM5 alleles $1-5$ in restricting SIV infection and the impact of this restriction on the clinical outcome of SIV infection in vivo [28]. Although MHC class I, TRIM5 and KIR3DH genes are encoded on different chromosomes in rhesus monkeys, contributions to SIV control by one allele could be a surrogate for the effects of another allele, as seen for $C C L 3 L$ and $M a m u-A * 01$ [29]. We found that $K I R 3 D H$ copy numbers were not significantly different between $M a m u-A^{*} 01^{+}$and $M a m u-A^{*} 01^{-}$rhesus monkeys (Mann-Whitney, $P=0.31$ ) (Figure 2B). Moreover, KIR3DH copy numbers were also not significantly different between $M a m u-B * 17$ and Mamu- $B^{*} 17^{+}$monkeys (Mann-Whitney, $P=0.49$ ). There were insufficient $M a m u-B^{*} 08^{+}$animals $(\mathrm{n}=3)$ in this cohort to assess the associations of this allele with $K I R 3 D H$ copy numbers. Finally, we found that $K I R 3 D H$ copy numbers were not significantly different in rhesus monkeys expressing only TRIM5 alleles $1-5$ and rhesus monkeys expressing at least one of the permissive TRIM5 alleles 6-11 (Mann-Whitney, $P=0.75$ ), nor were they significantly different when considering the four subsets of Mamu- $A^{*} 01$ and TRIM5 (Kruskal-Wallis, $P=0.19$ ).

High KIR3DH copy numbers are associated with lower peak SIV RNA levels in Mamu- $A^{*} 01^{-}$rhesus monkeys

To explore whether copy number variation of activating $K I R 3 D H$ alleles in rhesus monkeys might be associated with protection against SIV replication, we evaluated a cohort of 57 rhesus monkeys infected with SIVmac251. SIV plasma RNA levels were measured in these monkeys at peak and set-point of the infection, days 14 and 70 post-SIV challenge, respectively, since these measures of viremia have been shown to be predictors of SIV disease progression in rhesus monkeys [30,31]. No association of KIR3DH copy numbers and viral load at peak (Figure $3 \mathrm{~A}$ ) or setpoint (data not shown) was observed. To explore further a possible relationship between activating KIR copy numbers and control of SIV replication in vivo, we divided this cohort of rhesus monkeys into two groups based on their expression or lack of expression of the MHC class I allele Мати- $A^{*} 01$. Since its expression can 
B Mamu-A*01+

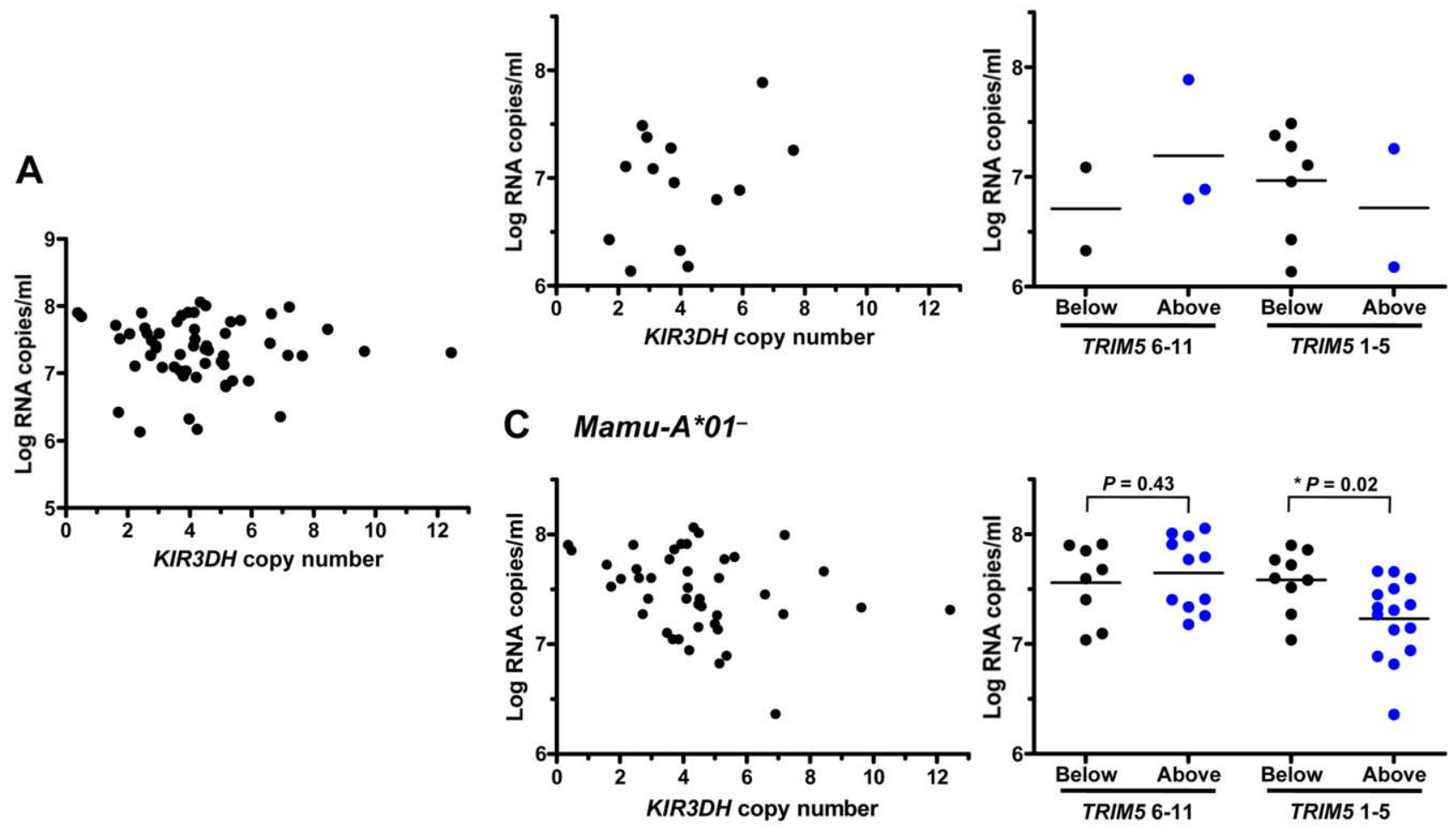

Figure 3. Association of $K I R 3 D H$ copy numbers and peak plasma SIV RNA levels in Indian-origin rhesus monkeys. $K I R 3 D H$ copy numbers were determined by quantitative real-time PCR using genomic DNA from rhesus monkeys. Peak plasma SIV RNA levels were quantified on day 14 post-SIVmac251-infection. Scatter plots represent the relationship between SIV peak viral load and KIR3DH copy numbers in the entire cohort of rhesus monkeys $(P=0.70)(\mathrm{A})$, in Mamu- $A^{*} 01^{+}$rhesus monkeys $(P=0.24)(\mathrm{B})$ and in Mamu- $A^{*} 01^{-}$rhesus monkeys $(P=0.08)(\mathrm{C})$. The $M a m u-A^{*} 01^{+}$ and $M a m u-A^{*} 01^{-}$rhesus monkeys were subdivided into two groups: one group having KIR3DH copy numbers below the median (black) and the other group having $\mathrm{KIR} 3 \mathrm{DH}$ copy numbers above the median (blue). These groups were further subdivided into monkeys expressing only TRIM5 alleles 1-5 or expressing at least one TRIM5 allele of the group 6-11. P values were determined using the Mann-Whitney $\mathrm{U}$ test (two-tailed). doi:10.1371/journal.ppat.1002436.g003

contribute to SIV control, we reasoned that the expression of Мати $-A^{*} 01$ might mask effects of other host alleles on controlling viral replication during SIV infection. On the basis of similar reasoning, the $М а т u-A^{*} 01^{+}$and $M a m u-A^{*} 01^{-}$rhesus monkeys were further divided into monkeys expressing only the TRIM5 alleles 1-5 and monkeys expressing at least one TRIM5 allele from the group 6-11. Finally, the monkeys were further subdivided into those having $K I R 3 D H$ copy numbers above the median $(\geq 4.111$ copies pdg) and those having KIR3DH copy numbers below the median $\left(<4.111\right.$ copies pdg). As expected, the Mamu- $A^{*} 01^{+}$ monkeys had lower viral load values at peak and set-point than the Мати $-A^{*} 01^{-}$monkeys (data not shown). In Мати- $A^{*} 01^{+}$rhesus monkeys, even when those monkeys were divided according to their TRIM5 allele expression, there was no association between KIR3DH copy numbers and peak (Figure $3 \mathrm{~B}$ ) or set-point (data not shown) viral load. However, there were too few monkeys with TRIM5 alleles 1-5 to determine whether there was such an association. Strikingly, in the $M a m u-A^{*} 01^{-}$rhesus monkeys, we observed a very strong negative trend toward an association between KIR3DH copy numbers and peak plasma SIV RNA levels $(P=0.08)$ (Figure 3C). The association between KIR3DH copy numbers and peak plasma SIV RNA levels was even more pronounced in $M a m u-A^{*} 01^{-}$rhesus monkeys expressing only the TRIM5 alleles $1-5$. In this group of monkeys, animals having KIR3DH copy numbers above the median had significantly lower peak SIV RNA levels than animals having $K I R 3 D H$ copy numbers below the median (Mann-Whitney, $P=0.02$ ), with a $0.4 \log$ median difference. We also analyzed the association between KIR3DH copy number and peak plasma viral load by fitting the data to a parabola or a linear spline with a fixed knot at a $K I R 3 D H$ copy number of 5 . The fixed knot of 5 was chosen because of previous reports that an individual NK cell usually expresses $3-5$ KIRs that are randomly selected on their surface [32]. We hypothesized that $K I R 3 D H$ copy numbers above 5 might not be associated with a linear increase in surface expression of KIR3DH molecules. In the Mamu- $A^{*} 01^{-}$, TRIM5 1-5 expressing monkeys, we observed comparable significance for the coefficient of the linear term in the parabola and for the slope of the spline for copy number $\leq 5(\mathrm{P}=0.015$ and $\mathrm{P}=0.016)$, the squared term in the parabola and the slope of the second spline were not significant $(\mathrm{P}=0.074$ and $\mathrm{P}=0.53)$ (Supplementary Figure $\mathrm{S} 2$ in Text $\mathrm{S} 1$ ). Interestingly, this association was no longer apparent by the time viral set-point was reached on day 70 post-infection (data not shown). These results suggest that NK cells from this subset of monkeys expressing higher numbers of KIR $3 D H$ copies may contribute more to control of SIV replication than NK cells from monkeys expressing lower numbers of activating KIR copies.

\section{$K I R 3 D H C N V$ is not associated with other clinical sequelae} of SIV infection

We then assessed some of the clinical consequences of SIV infection in Mamu- $A^{*} 01^{-}$rhesus monkeys. The loss of peripheral 
blood $\mathrm{CD} 4^{+} \mathrm{T}$ cells, and more importantly, central memory (CM) $\mathrm{CD}^{+} \mathrm{T}$ cells following SIV infection have been shown to predict survival of the infected rhesus monkeys [31]. Therefore, we evaluated the loss of peripheral blood $\mathrm{CD} 4^{+} \mathrm{T}$ cells and central memory $(\mathrm{CM}) \mathrm{CD}^{+} \mathrm{T}$ cells on days 14 (peak) and 70 (set-point) following SIVmac251 infection in these monkeys. Data were assessed by dividing the Mamu- $A^{*} 01^{-}$rhesus monkeys into those having KIR3DH copy numbers above the median $(\geq 4.11$ copies pdg) and those having KIR3DH copy numbers below the median $\left(<4.11\right.$ copies pdg). Neither loss of total $\mathrm{CD}^{+} \mathrm{T}$ cells nor loss of $\mathrm{CM} \mathrm{CD} 4^{+} \mathrm{T}$ cells was significantly associated with $K I R 3 D H$ copy numbers in these monkeys (Figure 4A, B). We also evaluated survival as a clinical indicator of long-term protection following SIV infection in the $М а т и-A^{*} 01^{-}$rhesus monkeys. Assessing the percentage of monkeys that had died by day 283 following SIV infection (day 283 was chosen ahead of time; after 283 days some monkeys were euthanized and some monkeys were used in other experiments), we observed no association between KIR3DH copy numbers and survival following infection (data not shown). Therefore, peak viral load was the only clinical correlate of $K I R 3 D H$ copy numbers in this cohort of monkeys.

\section{$K I R 3 D H$ CNV is not associated with the expression of particular $K I R 3 D H$ alleles}

Since some reports by other investigators had suggested that particular KIR alleles were associated with high plasma viral RNA levels in SIV-infected rhesus monkeys [20,33], we investigated whether particular KIR3DH alleles contributed to the association between KIR3DH copy numbers and control of peak SIV RNA levels in these monkeys. Full-length KIR3DH cDNA clones generated from 8 unrelated, Мати- $A^{*} 01^{-}$rhesus monkeys with different $K I R 3 D H$ copy numbers ranging from 1-10 copies pdg were acquired by PCR. Two of the isolated KIR cDNA sequences were identical to rhesus monkey KIR alleles that had previously been reported (Mamu-KIR3DS10-fHB-HQ (GU112262) and Mamu-KIR3DS05-fHH-HH (GU112301)) [19]. The majority of isolated KIR cDNA clones differed in their sequences from previously reported rhesus monkey KIR sequences. These novel sequences have been assigned the GenBank accession numbers JN613291-JN613300. The predicted amino acid sequences of all
KIR3DH alleles were aligned (Supplementary Figure S1 in Text $\mathrm{S} 1)$. While some $K I R 3 D H$ cDNA sequences were only observed in individual monkeys (eg. JN613291), other KIR3DH alleles were observed in multiple monkeys (eg. JN613292) (Figure 5). Importantly, there was no apparent trend toward certain $K I R 3 D H$ alleles being expressed in rhesus monkeys with low or high KIR3DH copy numbers. Therefore, there was no evidence that a particular $K I R 3 D H$ allele was responsible for the observed effect on early SIV control.

Higher KIR3DH copy numbers associate with high and stable $K I R 3 D H$ transcript levels

To assess how activating KIR GNV might affect early SIV containment, we first determined the association between the number of KIR3DH copies in a cell and the expression of KIR3DH genes by that cell. We utilized the qPCR assay that we developed for determining $K I R 3 D H \mathrm{CNV}$ to measure $K I R 3 D H$ mRNA expression levels in peripheral blood $\mathrm{CD}_{1} 6^{+} \mathrm{NK}$ cells of 28 naïve rhesus monkeys. Relative KIR3DH mRNA expression was significantly associated with $K I R 3 D H$ copy numbers in the evaluated cell populations, as determined by linear regression analysis $\left(P=<0.001, \mathrm{R}^{2}=0.51\right)$ (Figure 6A). To determine if these differences in KIR3DH RNA expression levels persisted over time, we sampled 15 of these naïve rhesus monkeys one month later, and KIR3DH RNA expression levels at both sampling dates were measured in the same qRT-PCR run. Relative mRNA expression levels of $K I R 3 D H$ genes from the first and second sampling associated positively, reaching statistical significance as determined by linear regression analysis $\left(P=0.03, \mathrm{R}^{2}=0.33\right.$ ) (Figure $6 \mathrm{~B}$ ). These findings suggest that increased $K I R 3 D H$ copy numbers associate with high, stable $K I R 3 D H$ mRNA expression levels.

KIR3DH CNV and NK cell frequencies on day 28 following SIV infection

We next investigated the relative representation of various subpopulations of NK cells in rhesus monkeys expressing different numbers of $K I R 3 D H$ copies. Rhesus monkey NK cells were defined as $\mathrm{CD}^{-} \mathrm{CD}^{-} \alpha^{+} \mathrm{NKG}^{+} \mathrm{A}^{+}$, and $\mathrm{CD} 16$ and $\mathrm{CD} 56$ expression were used to delineate three NK cell subsets: CD16 ${ }^{+}$,
A

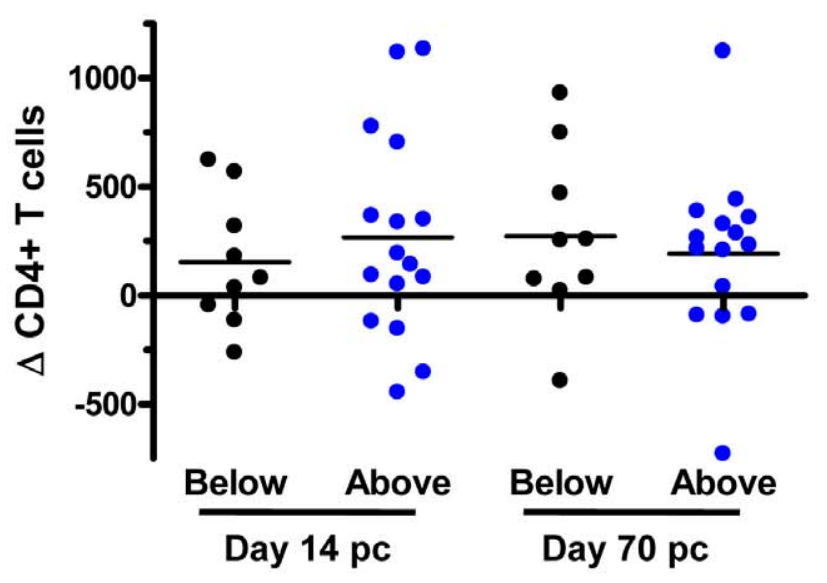

B

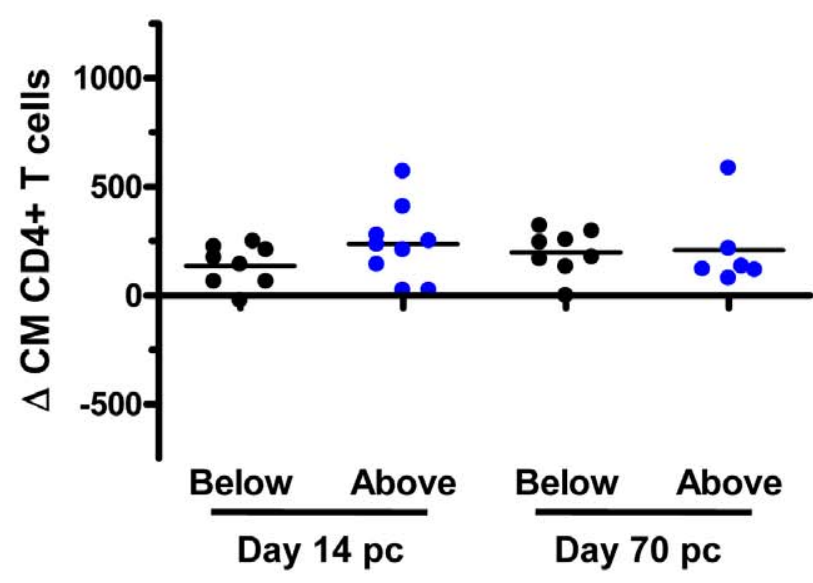

Figure 4. Lack of association between $K I R 3 D H$ copy numbers and clinical course following SIVmac251 infection in $M a m u-A * O T$ rhesus monkeys. Peripheral blood $\mathrm{CD}^{+} \mathrm{T}$ cell and central memory $(\mathrm{CM}) \mathrm{CD} 4^{+} \mathrm{T}$ cell counts were measured by flow cytometry and complete blood counting. Loss of $C D 4^{+} \mathrm{T}$ cells (A) and CM CD4 ${ }^{+} \mathrm{T}$ cells (B) were determined on days 14 and 70 post-challenge (pc). The Mamu- $A^{*} 01^{-}$rhesus monkeys were divided into two groups: monkeys having KIR3DH copy numbers below (black) or above (blue) the median. doi:10.1371/journal.ppat.1002436.g004 


\begin{tabular}{|c|c|c|c|c|c|c|c|c|}
\hline Rhesus ID & $392-02$ & D324 & $132-09$ & $400-08$ & $336-09$ & $338-09$ & $343-09$ & CP1B \\
\hline KIR3DH CNV & 1 & 2 & 3 & 4 & 5 & 6 & 7 & 10 \\
\hline JN613296 & & & & & & & & + \\
\hline JN613294 & & & & & & & & + \\
\hline JN613300 & & & & & + & & & \\
\hline JN613297 & & & & + & & & & \\
\hline JN613295 & & & & & & & & + \\
\hline JN613292 & & + & & & & & & + \\
\hline JN613298 & & & & & & + & + & \\
\hline JN613291 & & & + & & & & & \\
\hline JN613299 & & & & & + & + & & \\
\hline GU112301 & & & & & & & + & \\
\hline JN613293 & & + & & & & & + & \\
\hline GU112262 & + & & & & & & & \\
\hline
\end{tabular}

Figure 5. Expression of particular $K I R 3 D H$ alleles is not associated with $K I R 3 D H$ copy numbers. $K I R 3 D H$ cDNA clones of 8 unrelated rhesus monkeys with KIR3DH copy numbers ranging from 1-10 copies pdg were obtained using a PCR method described by Blokhuis et al. [18]. Two previously reported KIR alleles (GU112262, GU112301) and ten novel KIR3DH alleles (JN613291-JN613300) were identified. doi:10.1371/journal.ppat.1002436.g005

$\mathrm{CD}^{+} 6^{+}$and double-negative (DN) NK cells (Figure 7A). Since these subsets have been previously shown to mediate different effector functions, an expansion or contraction might only be expected to occur in certain NK cell subsets. The relative representation of $\mathrm{NK}$ cells, as a percentage of total circulating lymphocytes, and of NK cell subsets, as a percentage of total NK cells, were determined by flow cytometric analysis of PBMCs of naïve monkeys and of monkeys sampled on day 28 following SIVmac251 infection (Figure 7B). Data were displayed by grouping the monkeys into those having $K I R 3 D H$ copy numbers below and those having KIR3DH copy numbers above the median. In the naive rhesus monkeys, the relative representation of circulating NK cells did not associate with differences in KIR3DH copy numbers. We observed a modest increase in the relative representation of $\mathrm{NK}$ cells in monkeys harboring a greater number of KIR3DH copies than the median on day 28 post-SIVmac251 infection (median, 9.27\%; range, 2.15-15.82\%; n=9) compared to monkeys having KIR3DH copy numbers below the median
A

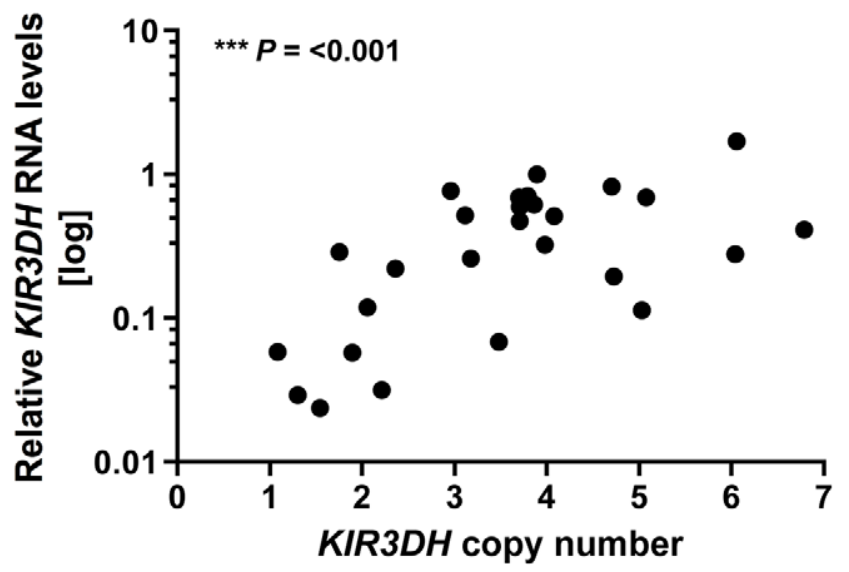

B

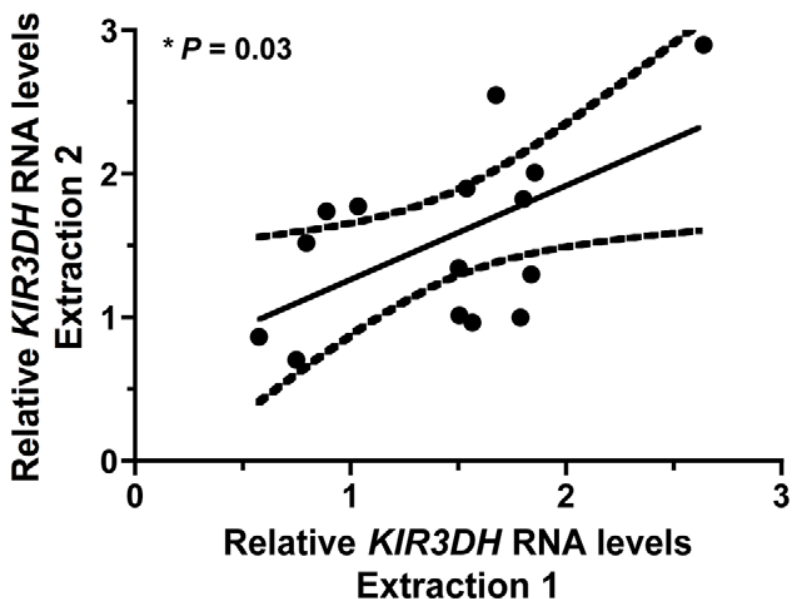

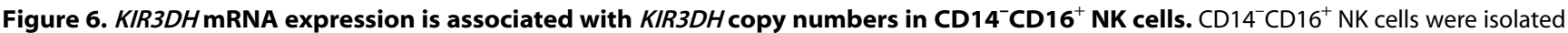
from PBMCs of naïve rhesus monkeys using immunomagnetic beads. RNA was extracted from these isolated cells and KIR3DH mRNA expression levels were determined by quantitative RT-PCR. Relative RNA expression was calculated using the $2^{-\Delta \Delta C P}$ method. (A) Scatter plots show the association between $K I R 3 D H$ copy numbers and $K I R 3 D H$ mRNA expression levels $\left(P=<0.001, R^{2}=0.51\right)$. (B) $K I R 3 D H$ mRNA expression levels were measured a second time in the same animals after a one month interval $\left(P=0.03, \mathrm{R}^{2}=0.33\right)$.

doi:10.1371/journal.ppat.1002436.g006 
A
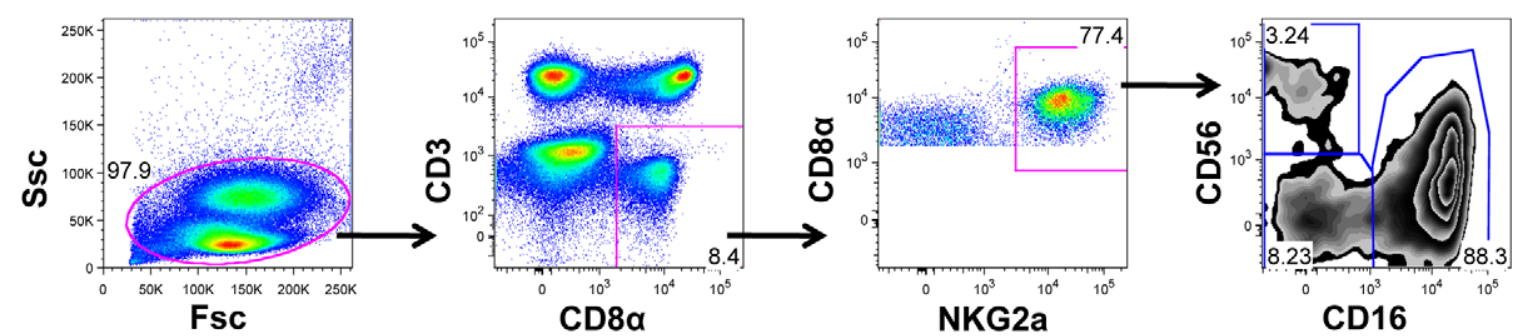

B
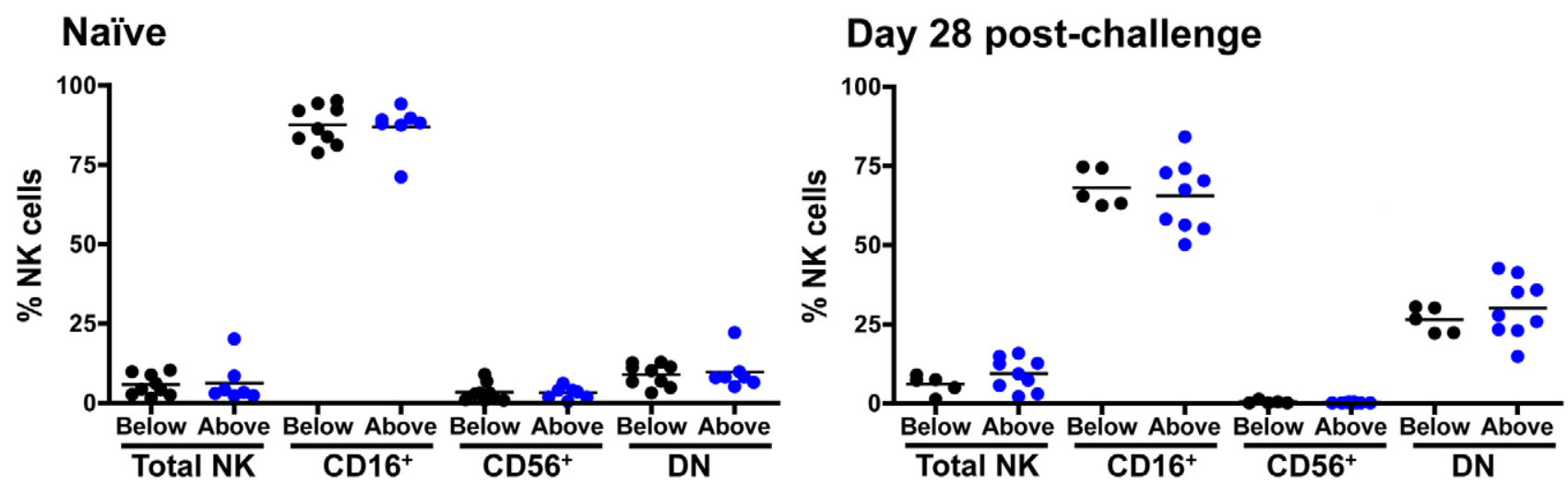

Figure 7. Distribution of peripheral blood NK cell subsets in Mamu- $A^{*} 01^{-}$rhesus monkeys. (A) Representative flow cytometric plots defining NK cells. Rhesus monkey NK cells were defined as CD3 ${ }^{-} \mathrm{CD} 8 \alpha^{+} \mathrm{NKG} 2 \mathrm{~A}^{+}$, and CD16 and CD56 expression was used to delineate three primary NK cell subsets: $\mathrm{CD} 16^{+}, \mathrm{CD} 56^{+}$and double negative (DN) NK cells. (B) Percentages of circulating total NK cells as well as CD16 ${ }^{+}, \mathrm{CD}^{+} 6^{+}$and doublenegative (DN) NK cells were compared in naïve rhesus monkeys and SIVmac251-infected rhesus monkeys on day 28 post-challenge. The rhesus monkeys were divided into animals having KIR3DH copy numbers below (black) or above (blue) the median.

doi:10.1371/journal.ppat.1002436.g007

(median, 6.02\%; range, $1.34 \%-9.04 \% ; \mathrm{n}=5$ ). However, this difference in circulating NK cells did not reach statistical significance (Mann-Whitney, $P=0.24$ ). Since there is no available antibody for staining KIR3DH molecules, NK cells that express KIR3DH receptors on their surface can't be distinguished from those that do not.

\section{Cytokine production of stimulated NK cell}

subpopulations and expression of NK cell activation molecules does not associate with KIR3DH CNV

We finally assessed some aspects of the functionality of NK cells from rhesus monkeys harboring different copy numbers of KIR3DH loci. We evaluated cytokine secretion by NK cells from naïve and SIVmac251-infected monkeys in response to in vitro stimulation. PBMGs were stimulated with K562 cells and the intracellular expression of two cytokines produced by NK cells tumor necrosis factor $\alpha(\mathrm{TNF} \alpha)$ and interferon $\gamma($ IFN $\gamma)$ - was measured in the three primary NK cell subsets: CD16 ${ }^{+}, \mathrm{CD}^{+} 6^{+}$ and DN NK cells. As expected, the CD16 ${ }^{+} \mathrm{NK}$ cells secreted little cytokine [34], while the other NK cell subpopulations did secrete cytokines upon stimulation (Figure 8). There was, however, no obvious association between $\mathrm{TNF} \alpha$ or $\mathrm{IFN} \gamma$ secretion upon stimulation and $K I R 3 D H$ copy numbers by the $\mathrm{CD}^{-} 6^{+}$and $\mathrm{DN}$ NK cell subpopulations. This was seen in NK cells sampled from both naïve and recently infected monkeys (Figure 8A, B and data not shown).

We also assessed whether the surface expression of the activation-associated molecules CD69, HLA-DR and NKp46 on NK cell subsets was associated with $K I R 3 D H$ copy numbers in naïve rhesus monkeys and in the same cohort of monkeys at day 35 and at set-point following SIV infection. The intracellular levels of the proliferation-associated Ki67 molecule in NK cells during primary infection were also assessed. No association was observed between KIR3DH copy number and the expression of these molecules in $\mathrm{CD} 6^{+}, \mathrm{DN}$ or $\mathrm{CD} 56^{+} \mathrm{NK}$ cells pre- or post-infection (Supplementary Figure S3 in Text S1 and data not shown).

\section{Discussion}

The protective effects of particular KIRs for HIV-1 infections in humans have, for the most part, been shown in epidemiologic studies [12,35-37]. Functional studies of NK cells expressing specific KIRs have been difficult to carry out in the early phases of HIV-1 infections because the timing of HIV-1 acquisition cannot be precisely determined from the clinical histories of patients. The SIV-infected rhesus monkey therefore represents a potentially important model for studying KIR receptors expressed on the surface of NK cells and the effects of these cells on the control of viral replication during primary infection. However, the ligands of rhesus monkey KIRs are not well understood. The interaction between a particular KIR and its ligand might, however, be crucial for that KIR to modify disease outcome in HIV-1/SIV infections. In fact, some reports suggest that associations between particular KIR receptors and clinical sequelae of HIV-1 infections are only observed when the ligands of those KIRs are considered $[12,36,38]$. For example, coexpression of KIR3DS1 and its ligand $H L A-B$ Bw4-80Ile alleles was associated with a delayed progression to AIDS in HIV-1-infected individuals, whereas the expression of KIR3DS1 in the absence of the HLA-B Bw4-80Ile alleles was not 


\section{A Naïve}
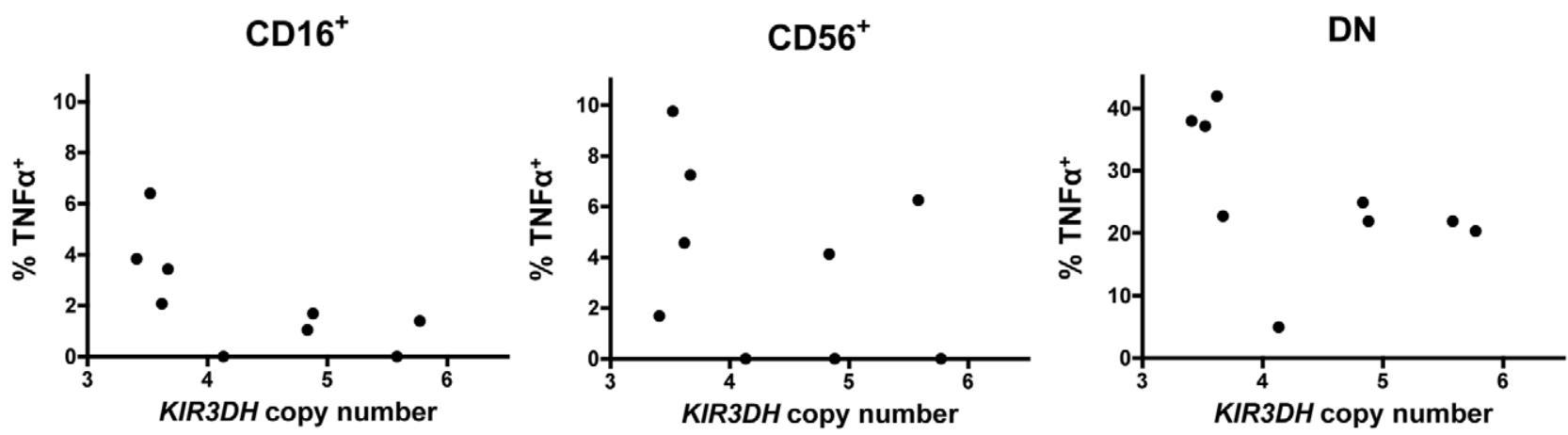

\section{B Day 28 post-challenge}
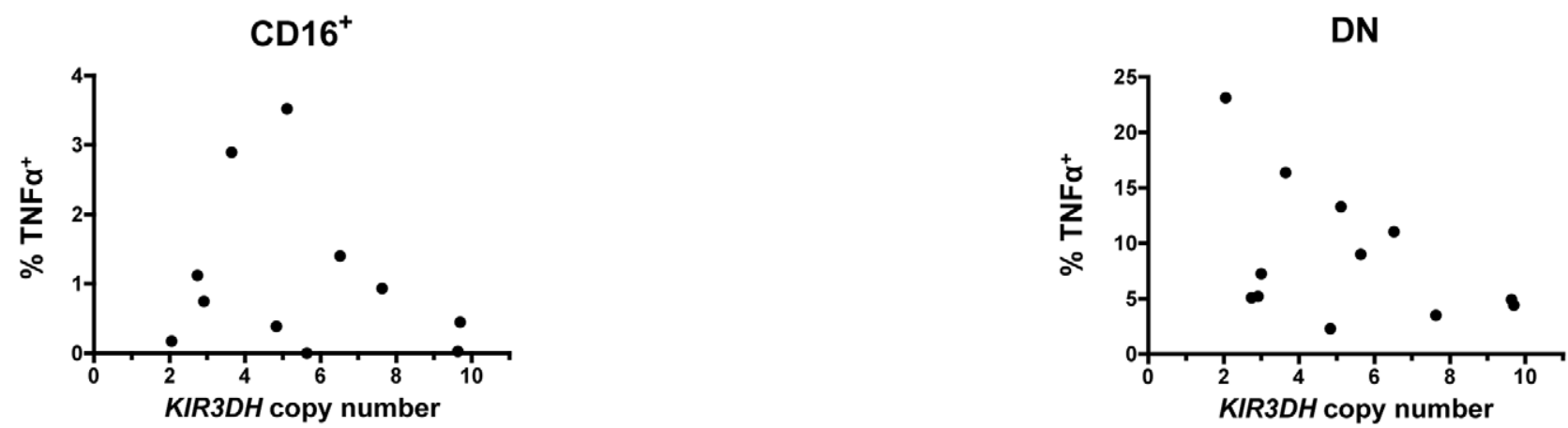

Figure 8. Secretion of tumor necrosis factor $\alpha$ (TNF $\alpha)$ in NK cell subsets following stimulation with K562 cells. PBMCs were stimulated with K562 cells at an effector-to-target-ratio of 10:1. Percentages of TNF $\alpha^{+}$cells above background in CD16 ${ }^{+}, \mathrm{CD}^{+} 6^{+}$and DN NK cells were measured in peripheral blood of naïve rhesus monkeys (A) and SIVmac251-infected rhesus monkeys on day 28 post-challenge (B). For the day 28 post-challenge timepoint, insufficient $\mathrm{CD} 56^{+}$NK cells were acquired to allow an analysis.

doi:10.1371/journal.ppat.1002436.g008

associated with a delayed clinical progression following HIV-1 infection [12]. In contrast to this observation, other studies in humans have demonstrated that the expression of particular KIR molecules was associated with a more favorable HIV-1 disease outcome or decreased risk of HIV-1 acquisition irrespective of the expression of the KIR ligands [37,39,40]. Also, studies of SIVinfected rhesus monkeys showed that the expression of particular inhibitory KIR3DL and KIR3DH molecules was associated with high levels of SIV replication without consideration of the ligands of those KIR molecules [20,33]. Consistent with the findings of these latter studies, we observed an association between KIR3DH copy numbers and peak SIV RNA levels during primary infection in monkeys that did not express Mamu- $A^{*} 01$ and expressed the restrictive TRIM5 alleles 1-5 without considering the contribution of specific KIR ligands. It is possible however, that the observed effect might be more profound if KIR3DH ligands were taken into consideration.

The characterization of KIR3DH-expressing NK cell subpopulations could be important for clarifying the role of activating KIRs in modulating SIV replication. There is, however, no monoclonal antibody that recognizes rhesus monkey KIR3DH, and, therefore, surface expression of KIR3DH on monkey NK cells cannot be monitored. Without such an antibody, NK cells expressing high levels of KIR3DH molecules on their surface and high frequencies of $\mathrm{KIR} 3 \mathrm{DH}^{+} \mathrm{NK}$ cells cannot be distinguished. In the present studies, we used $K I R 3 D H$ RNA expression as a surrogate for KIR3DH cell surface expression. The primer/probe set used in the assay to quantify $K I R 3 D H$ RNA expression binds to a conserved region of the $K I R 3 D H$ genes that encodes the transmembrane domain of the KIR3DH proteins. Therefore, truncated KIR proteins that have lost their transmembrane domains due to frameshift deletions and are not anchored in the cell membrane, as seen for allotypes of the human KIR2DS4 and KIR2DL4 [41,42], would not be detected. We assume that higher $K I R 3 D H$ copy numbers, and the resulting higher $K I R 3 D H$ transcript levels, indicate an increased surface expression of activating KIR receptors on subpopulations of NK cells.

The MHC class I allele Mamu-A*01 and TRIM5 alleles are genetic determinants of the control of SIV replication in rhesus monkeys $[25,29,43]$. A link was also reported between CCL3L GNV and AIDS progression in SIV-infected rhesus monkeys [22]. We, however, showed that CCL3L CNV was serving as a surrogate for the expression of Mamu- $A^{*} 01$, and the relatively benign clinical course observed following SIV infection in certain monkeys was actually a consequence of $M a m u-A * 01$ expression by those animals [29]. Because of these findings, it was important in the present studies to show that $K I R 3 D H$ copy numbers were not acting as a surrogate marker for the Мати- $A^{*} 01$ and TRIM5 status of the monkeys. In our data, CNV of KIR3DH was not associated with the expression of either Мати-A*01, Мати- $B^{*} 17$ or the restrictive TRIM 5 alleles. In addition, when Mamu- $A^{*} 01$ and TRIM5 were both included in models, they did not eliminate the relationship of KIR3DH copy number and peak viral load. 
Very few studies have evaluated CNV in KIR loci. One study showed that KIR2DS2 copies ranged from 0 to 2 copies in humans [38]. In that study, KIR2DS2 copy numbers were estimated using KIR typing rather than single gene analysis. Pelak et al. documented up to 3 copies of KIR3DS1 and 3 copies of KIR3DL1 in humans using a qPCR-based assay that was similar to the quantitative assay we used in the present studies [Pelak et al., personal communication]. We, however, observed a wider range of KIR3DH copies in rhesus monkeys with one monkey having 12 KIR3DH copies per cell. We defined copy numbers of the KIR3DH family without evaluating individual KIR3DH genes. These results are consistent with a recent study in rhesus monkeys showing 0-4 KIR3DS genes per haplotype [19].

Both Gaudieri et al. and Pelak et al. investigated the effects of copy number variation of KIR2DS2 and KIR3DS1 on HIV-1 disease outcome. Higher copy numbers of the activating KIR2DS2 were associated with greater $\mathrm{CD}^{+} \mathrm{T}$ cell loss and rapid progression to AIDS [38]. Since these investigators only indirectly determined KIR2DS2 copy numbers and there is a strong linkage disequilibrium between KIR2DS2 and KIR2DL2, the rapid HIV-1 disease progression in these individuals might not be attributable to the expression of KIR2DS2. In the study by Pelak et al., higher numbers of activating KIR3DS1 copies were associated with lower plasma virus RNA levels at set-point in HIV-1 infected individuals that express the KIR3DS1-ligand HLA-B Bw4-80Ile alleles [Pelak et al., personal communication]. The findings in the present study are in line with these observations.

The effect of activating KIR copy numbers on SIV replication may be more modest than the effects on SIV control mediated by the MHC class I molecule $M a m u-A * 01$ and the restrictive TRIM5 alleles $[25,28,43]$. Since the KIR3DH copy number effect was only seen in the $M a m u-A^{*} 01^{-}$monkeys that were homozygous for restrictive TRIM 5 alleles, it is likely that a stronger Mamu- $A^{*} 01$-associated effect may obscure this NK cell contribution to SIV control. It is not immediately obvious why the $K I R 3 D H$ copy number effect was only observed in the monkeys expressing the restrictive TRIM5 alleles.

In the present studies we showed that higher numbers of KIR3DH copies were associated with lower peak viral load following SIV infection, but we did not observe associations between KIR3DH copy numbers and other clinical sequelae of SIV infection. The contributions of NK cells to the control of SIV replication may be manifested during the early stages of SIV infection. Then, during the course of SIV-infection, virus-specific $\mathrm{CD}^{+} \mathrm{T}$ cells expand that maintain control over viral replication throughout the chronic phase of infection [44-48]. The contributions of adaptive $\mathrm{CD}^{+} \mathrm{T}$ cells to viral replication are likely much greater than those mediated by NK cells, and these effects may simply obscure those of KIR3DH-expressing NK cells on SIV control during the later stages of infection. Further, the NK cells may become too dysfunctional later in the course of infections to mediate an antiviral effect [49-51].

\section{Materials and Methods}

\section{Ethics statement}

All of the animals used in this present study were Indian-origin rhesus macaques. All monkeys were housed in accordance with the guidelines of the NIH Guide for the Care and Use of Laboratory Animals and with the approval of the Institutional Animal Care and Use Committee of Harvard Medical School and the National Institutes of Health.

\section{Animals and SIV infections}

SIV-challenged monkeys were either infected intravenously or intrarectally with an uncloned SIVmac251 inoculum [31]. The expression of $М a m u-A * 01$, Мати- $B^{*} 08$, Матu- $B^{*} 17$ and the expression of TRIM5 alleles were assessed by PCR [28,29].

\section{Plasma viral load assay and $\mathrm{CD}^{+} \mathrm{T}$ lymphocyte counts}

Plasma viral RNA levels were measured using an ultra-sensitive branched DNA amplification assay (Bayer Diagnostics, Berkeley, CA). Counts of total peripheral blood $\mathrm{CD}^{+} \mathrm{T}$ lymphocytes and central memory $\mathrm{CD}^{+} \mathrm{T}$ lymphocytes were calculated by multiplying the total lymphocyte count by the percentage of $\mathrm{CD} 3^{+} \mathrm{CD} 4^{+} \mathrm{T}$ cells, times the percentage of $\mathrm{CD} 95^{+} \mathrm{CD} 28^{+} \mathrm{T}$ cells for counts of central memory $\mathrm{CD} 4^{+} \mathrm{T}$ cells, determined by monoclonal antibody staining and flow cytometric analysis [52].

\section{Extraction of genomic DNA}

Total genomic DNA was extracted from peripheral blood mononuclear cells (PBMCs) or H.papio-immortalized B-lymphoblastoid cell lines (B-LCLs) using the DNeasy Blood and Tissue Kit (Qiagen, Valencia, CA). The purity of the isolated genomic DNA was verified by $\mathrm{A}_{260 / \mathrm{A} 280}$ ratio: average 1.88 (range 1.74-2.00). The DNA samples were stored at $-20^{\circ} \mathrm{C}$ until use. DNA integrity was verified by gel-electrophoresis of selected samples.

\section{Determination of $K I R 3 D H$ copy numbers using real-time PCR}

Activating KIR copy number determinations were performed by quantitative real-time PCR (qPCR) using the 7300 Real-time PCR System (Applied Biosystems, Foster City, CA). With KIR3DH being the only activating KIR receptor family in rhesus monkeys, a KIR3DH primer and TaqMan probe set for qPGR was designed to specifically amplify previously identified Mm-KIR3DH alleles (GenBank accession numbers MmKIR3DH1-4 (AF334648AF334651), MmKIR3DH7-21 (EU702453-EU702473), and MmKIR3DH-like1-4 (AY505479-82)) [17,18], thereby avoiding recognition of any inhibitory KIR genes. KIR3DH-specific primer sequences were: Forward: 5'-CACGAGACACGTGCCTATTGTGA-3'; Reverse: 5'-GAGTCTCTTTTTGTCGGAGCACGA3'; Probe: 5'-FAM-TAGGTAGTCGGTGGCGACGATCATBHQ-3'. qPCR products were sequenced to confirm the specificity of the amplification. The STAT6 gene, present in a single copy per haploid rhesus genome [22], was used as an endogenous reference gene: Forward: 5'-AACGTAAAGAGAATGGGAGTGT-3'; Reverse: 5'-GAATATAGTGACAACCCTGGATC-3'; Probe: 5'-FAM-CTCTGCCCTTCTCGTGCGTCCG-BHQ-3' Primers were purchased from Invitrogen and probes were purchased from Biosearch Technologies. Per qPCR reaction, $12.5 \mathrm{ng}$ of total genomic DNA were added to TaqMan Universal PCR Master Mix (Applied Biosystems) and the specific primers and probe. All samples were run in triplicate. Thermal cycling conditions were as follows: $2 \mathrm{~min}$ at $50^{\circ} \mathrm{C}, 10 \mathrm{~min}$ at $95^{\circ} \mathrm{C}$, followed by 40 cycles of a two-step PCR of $15 \mathrm{~s}$ at $95^{\circ} \mathrm{C}$ and $1 \mathrm{~min}$ at $60^{\circ} \mathrm{C}$. $\mathrm{qPCR}$ results were analyzed using the SDS v1.4.0 software (Applied Biosystems).

\section{Absolute quantification of $K I R 3 D H$ copy numbers using plasmid standard}

To determine absolute KIR3DH copy numbers, plasmid DNA standards for KIR3DH and STAT6 were created. The plasmids contained the specific sequence amplified in the qPGR reaction. KIR3DH standard primers were: Forward 5'-GGAGGAACCTACAGATGCTTCG-3'; Reverse: 5'-TGAGAGTCTCTTTTTGTCGGAGCAC-3'. STAT6 standard primers were: Forward: 5'CCTTGTCGAAACTGAGTCGAACTGG-3'; Reverse: 5'-CAGACGCAGGACGTCAGACTTC-3'. 
First-strand cDNA was synthesized from RNA isolated from rhesus PBMCs using an oligo $(\mathrm{dT})_{20}$ primer and the SuperScript III First-Strand Synthesis System for RT-PCR (Invitrogen, Carlsbad, CA), following the manufacturer's protocol. Then, PCR was performed using the Platinum PGR SuperMix High Fidelity (Invitrogen). Amplification conditions were: $5 \mathrm{~min}$ at $94^{\circ} \mathrm{C} ; 35$ cycles of $30 \mathrm{~s}$ at $94^{\circ} \mathrm{C}, 30 \mathrm{~s}$ at $55^{\circ} \mathrm{C}$, and $45 \mathrm{~s}$ at $68^{\circ} \mathrm{C}$; and $20 \mathrm{~min}$ at $68^{\circ} \mathrm{C}$. PCR products were resolved by gel electrophoresis, excised and purified with the QIAquick Gel Extraction Kit (Qiagen). Purified PCR products were ligated into the pGEM-T Easy Vector (Promega, Madison, WI), resulting in pKIR3DH and pSTAT6. Clones containing the correct insert were verified by sequencing. Plasmids were isolated and purified using the EndoFree Plasmid Maxi Kit (Qiagen), and the plasmid DNA concentration was measured using a NanoDrop ND-1000 spectrophotometer (Thermo Scientific, Wilmington, DE). Six serial $\log$ dilutions $\left(10^{8}-10^{3}\right.$ copies $)$ of pKIR3DH and pSTAT6 plasmid DNA were used to generate standard curves by plotting $\mathrm{C}_{\mathrm{T}}$ values versus $\log$ copies of each qPCR plate. An $\mathrm{R}^{2}$ value of a standard curve of less than $99 \%$ was considered imprecise and the corresponding qPCR plate (96 wells) of DNA samples was repeated. Absolute copy numbers were calculated by determining the number of KIR3DH copies per sample from the standard curve and then by normalizing against the number of STAT6 copies in the same sample. Values were multiplied by 2 to obtain copy numbers per diploid genome.

\section{Confirmation of qPCR KIR3DH copy number estimates}

To validate that the KIR $3 D H$ absolute copy numbers calculated from qPCR were accurate, we determined $K I R 3 D H$ copy numbers using a multiplex ligation-dependent probe amplification assay (MLPA). Two adjacent oligonucleotides per locus - one set for the KIR3DH loci and, as reference loci, two sets for EP300 (E1A binding protein p300) and one set for CREBBP (CREB-binding protein) - were designed to contain the same primer binding sequences for later amplification. Only one KIR3DH MLPA oligonucleotide set, recognizing the same $K I R 3 D H$ alleles as in the qPCR assay, could be designed due to the polymorphic nature of the KIR3DH loci. The oligonucleotide sequences are listed in the Supplementary Table S1 in Text Sl and were purchased from IDT (IDT, Coralville, IA). All MLPA reagents were purchased from MRG Holland (MRC-Holland, Amsterdam, Netherlands). The MLPA reaction was carried out according to the manufacturer's protocol using $100 \mathrm{ng}$ of genomic DNA. For each DNA sample, the oligonucleotide sets for the KIR $3 D H$ genes and the reference loci were ligated to the DNA in a multiplex PCR and only ligated oligonucleotides were amplified using the FAMlabeled universal primer pair. Amplified PCR products differed in length and could therefore be distinguished. The amplification products were analyzed on an ABI 3130XL capillary DNA analyzer (Applied Biosystems). The results were analyzed using GeneMapper Software (Applied Biosystems). The final analysis of the MLPA data was carried out using Microsoft Excel software. For each sample, peak signal values for $K I R 3 D H$ were normalized by the average signal of the reference probes to determine relative MLPA signals [53]. Relative MLPA signals from two different experiments using the same DNA samples formed discrete clusters corresponding to copy numbers. Absolute copy numbers of individual clusters were determined by assuming that the distance between successive clusters corresponded to 1 copy and that the copy number genotype of the first cluster corresponded to the distance from 0 divided by the average distance of successive clusters.

\section{RNA isolation}

PBMCs were sorted for $\mathrm{CD} 14^{-} \mathrm{CD} 16^{+} \mathrm{NK}$ cells using magnetic cell sorting (MACS Microbeads by Miltenyi Biotec). Total RNA was isolated from the $\mathrm{CD} 14^{-} \mathrm{CD}^{-} 6^{+} \mathrm{NK}$ cells using the RNeasy Mini Kit (Qiagen). RNA samples were stored at $-80^{\circ} \mathrm{C}$ until use.

\section{Quantification of KIR3DH RNA expression}

KIR3DH RNA expression in $\mathrm{CD} 14^{-} \mathrm{CD} 16^{+} \mathrm{NK}$ cells was determined by performing real-time quantitative reverse transcription PCR (qRT-PGR) using the same KIR3DH and STAT6 primers and probes used for copy number determination of DNA. Per qRT-PCR reaction, $50 \mathrm{ng}$ of total RNA was added to the Taqman One-Step RT-PCR Master Mix (Applied Biosystems) and the KIR3DH- and STAT6-specific primers and probes. All samples were run in triplicates. Thermal cycling conditions were as follows: $30 \mathrm{~min}$ at $48^{\circ} \mathrm{C}, 10 \mathrm{~min}$ at $95^{\circ} \mathrm{C}$, followed by 40 cycles of a twostep PCR of $15 \mathrm{~s}$ at $95^{\circ} \mathrm{C}$ and $1 \mathrm{~min}$ at $60^{\circ} \mathrm{C}$. qRT-PCR results were analyzed using the SDS v1.4.0 software (Applied Biosystems). Relative RNA expression was determined using the $2^{-\Delta \Delta \mathrm{Ct}}$ method (Applied Biosystems). Briefly, for each sample, $\mathrm{C}_{\mathrm{T}}$ values of KIR3DH were first normalized against the $\mathrm{C}_{\mathrm{T}}$ values of STAT6. Normalized KIR3DH $\mathrm{C}_{\mathrm{T}}$ values for each monkey were then divided by the normalized $K I R 3 D H \mathrm{C}_{\mathrm{T}}$ values of one reference monkey that was evaluated in each qPCR run to determine relative $K I R 3 D H$ RNA expression.

\section{Discrimination of $K I R 3 D H$ alleles}

Total RNA, isolated from rhesus $\mathrm{CD} 14^{-} \mathrm{CD} 16^{+} \mathrm{NK}$ cells, was used to synthesize first-strand cDNA using an oligo $(\mathrm{dT})_{20}$ primer and the SuperScript III First-Strand Synthesis System for RTPCR (Invitrogen), following the manufacturer's protocol. PCR amplification was performed using the Platinum PCR SuperMix High Fidelity (Invitrogen). The primer sequences were as described by Blokhuis et al. [18]. Amplification conditions were as follows: $5 \mathrm{~min}$ at $94^{\circ} \mathrm{C}$; 35 cycles of $30 \mathrm{~s}$ at $94^{\circ} \mathrm{C}, 30 \mathrm{~s}$ at $66^{\circ} \mathrm{C}$, and $90 \mathrm{~s}$ at $68^{\circ} \mathrm{C}$; and $20 \mathrm{~min}$ at $68^{\circ} \mathrm{C}$. PCR products were subjected to gel electrophoresis, excised and purified with a QIAquick Gel Extraction Kit (Qiagen) following the manufacturer's protocol. Purified PCR products were ligated into the pGEM$\mathrm{T}$ Easy vector (Promega), according to the manufacturer's instructions. Briefly, ligation reactions were incubated at room temperature for one hour and then transformed into JM109 High Efficiency competent cells (Promega). Between 23 and 28 insertcontaining colonies per sample were sequenced and analyzed using the Sequencher Software (Gene Codes, Ann Arbor, MI). Corresponding amino acid sequences were aligned using ClustalW2 Multiple Sequence Alignment [54]. Only KIR sequences that were obtained from more than one clone are reported. The novel rhesus monkey KIR cDNA sequences have been assigned the GenBank accession numbers JN613291-JN613300.

\section{Monoclonal antibodies (MAbs) and immunophenotyping of NK cells}

The antibodies used in this study were anti-CD8 $\alpha$-Peridinium Chlorophyll Protein-Cy5.5 (SK1), anti-CD56-Phycoerythrin-Cy7 (N901, Beckman Coulter, Brea, CA), anti-CD3-Pacific Blue (SP34.2), anti-CD159 (NKG2A)-Allophycocyanin (Z199, Beckman Coulter), anti-CD16-Allophycocyanin-Cy7 (3G8), anti-TNF $\alpha$-Fluorescein Isothiocyanate (MAb11), anti-IFN $\gamma$-Alexa Fluor 700 (B27) anti-CD335 (NKp46)-Phycoerythrin (BAB281, Beckman Coulter), anti-CD69-energy-coupled dye (TP1.55.3, Beckman Coulter), antiHLA-DR-Phycoerythrin-Cy7 (L243 (G46-6), anti-Ki67-Alexa Fluor 488 (B56), and anti-CD56-Peridinium Chlorophyll Protein-Cy5.5 
(B159). All antibodies unless otherwise indicated were purchased from BD Biosciences. The LIVE/DEAD Fixable Aqua Dead Cell stain kit (Invitrogen) was used as a viability marker to distinguish live cells from dead cells in all flow cytometric analyses. All acquisitions were made on a LSR II flow cytometer (BD Biosciences) and analyzed using FlowJo software (TreeStar Inc., Ashland, OR). PBMCs were isolated from EDTA-anticoagulated blood by FicollPaque (GE Healthcare, Piscataway, NJ) gradient separation and either stained immediately or cryopreserved in the vapor phase of liquid nitrogen. Later, cryopreserved cells were thawed and rested at $37^{\circ} \mathrm{C}$ in a $5 \% \mathrm{CO}_{2}$ environment for $6 \mathrm{hrs}$. The viability of these cells was $>90 \%$. PBMCs were stained with anti-surface MAbs to delineate NK cells (CD3, CD8, NKG2A, CD56, and CD16) and anti-surface molecules CD69, HLA-DR and NKp46. Cells were then fixed and permeabilized with Cytofix/Cytoperm solution (BD Biosciences) and stained with antibodies specific for Ki67. Labeled cells were fixed in $1 \%$ formaldehyde-PBS.

\section{PBMC stimulation and intracellular cytokine staining}

To determine cytokine production of NK cells in response to K562 cells, PBMC were incubated for 6 hours in the presence of RPMI 1640/10\% fetal calf serum alone (unstimulated), with K562 at an effector-to-target ratio of 10:1, or with phorbol myristate acetate (PMA) as a positive control. All samples contained Monensin (GolgiStop, BD Biosciences) and Brefeldin (Golgi Plug, BD Biosciences). Cells were next stained with antibodies specific for cell surface molecules CD3, CD8, NKG2A, CD56, and CD16. Cells were then fixed and permeabilized with Cytofix/Cytoperm solution (BD Biosciences) and stained with antibodies specific for $\mathrm{TNF} \alpha$ and IFN $\gamma$. Labeled cells were fixed in $1 \%$ formaldehydePBS. All data are reported after background correction.

\section{References}

1. Biron CA (1999) Initial and innate responses to viral infections--pattern setting in immunity or disease. Curr Opin Microbiol 2: 374-381.

2. Cerwenka A, Lanier LL (2001) Natural killer cells, viruses and cancer. Nat Rev Immunol 1: 41-49.

3. Orange JS (2002) Human natural killer cell deficiencies and susceptibility to infection. Microbes Infect 4: 1545-1558.

4. Lanier LL (2005) NK cell recognition. Annu Rev Immunol 23: 225-274.

5. Trinchieri G (1989) Biology of natural killer cells. Adv Immunol 47: 187-376.

6. Moretta A, Bottino C, Mingari MC, Biassoni R, Moretta L (2002) What is a natural killer cell? Nat Immunol 3: 6-8.

7. Vivier E, Nunes JA, Vely F (2004) Natural killer cell signaling pathways. Science 306: $1517-1519$

8. Moretta A, Sivori S, Vitale M, Pende D, Morelli L, et al. (1995) Existence of both inhibitory (p58) and activatory (p50) receptors for HLA-C molecules in human natural killer cells. J Exp Med 182: 875-884.

9. Pende D, Biassoni R, Cantoni C, Verdiani S, Falco M, et al. (1996) The natural killer cell receptor specific for HLA-A allotypes: a novel member of the p58/p70 family of inhibitory receptors that is characterized by three immunoglobulin-like domains and is expressed as a 140-kD disulphide-linked dimer. J Exp Med 184: 505-518.

10. Parham P (2005) MHC class I molecules and KIRs in human history, health and survival. Nat Rev Immunol 5: 201-214.

11. Martin MP, Carrington M (2005) Immunogenetics of viral infections. Curr Opin Immunol 17: 510-516.

12. Martin MP, Gao X, Lee JH, Nelson GW, Detels R, et al. (2002) Epistatic interaction between KIR3DS1 and HLA-B delays the progression to AIDS. Nat Genet 31: 429-434.

13. Alter G, Martin MP, Teigen N, Carr WH, Suscovich TJ, et al. (2007) Differential natural killer cell-mediated inhibition of HIV-1 replication based on distinct KIR/HLA subtypes. J Exp Med 204: 3027-3036.

14. Alter G, Rihn S, Walter K, Nolting A, Martin M, et al. (2009) HLA class I subtype-dependent expansion of KIR3DS1+ and KIR3DL1+ NK cells during acute human immunodeficiency virus type 1 infection. J Virol 83: 6798-6805.

15. Martin MP, Pascal V, Yeager M, Phair J, Kirk GD, et al. (2007) A mutation in KIR3DS1 that results in truncation and lack of cell surface expression. Immunogenetics 59: 823-829.

16. Haigwood NL (2004) Predictive value of primate models for AIDS. AIDS Rev 6: 187-198.

\section{Statistical analyses}

All statistical analyses and graphic analyses were conducted using GraphPad Prism (GraphPad Prism Software, La Jolla, CA) and STATA (StataCorp LP, College Station, Texas). Normality was assessed using the skewness test, the kurtosis test, the chisquared-test and the Shapiro-Wilks-test. The non-parametric Mann-Whitney-test was used for the comparison of two groups and the Kruskal-Wallis test was used for comparing more than two groups. Linear regression models were done for the relationship of peak viral load and KIR3DH copy number either overall (and incorporating covariates for Mamu- $A^{*} 01$ and TRIM5 groupings) or in subgroups. Subsequently, two other regression models (parabolic, i.e. second degree polynomial, and two linear splines with a fixed knot at 5) were used because of previous reports that an individual NK cell usually expressed at most 5 KIRs [32]. All $P$ values are two-sided and none are corrected for multiple comparisons. $P$ values of $<0.05$ were considered significant.

\section{Supporting Information}

Text S1 Supplementary figures and tables. $(\mathrm{PDF})$

\section{Acknowledgments}

We thank Yue Sun, Mary Carrington, David B. Goldstein and Piotr Kozlowski for helpful discussions.

\section{Author Contributions}

Conceived and designed the experiments: IH NLL. Performed the experiments: IH SYL. Analyzed the data: IH SYL RSG. Wrote the paper: IH NLL RSG.

17. Hershberger KL, Shyam R, Miura A, Letvin NL (2001) Diversity of the killer cell Ig-like receptors of rhesus monkeys. J Immunol 166: 4380-4390.

18. Blokhuis JH, Doxiadis GG, Bontrop RE (2009) A splice site mutation converts an inhibitory killer cell Ig-like receptor into an activating one. Mol Immunol 46: 640-648.

19. Blokhuis JH, van der Wiel MK, Doxiadis GG, Bontrop RE (2010) The mosaic of KIR haplotypes in rhesus macaques. Immunogenetics 62: 295-306.

20. Chaichompoo P, Bostik P, Stephenson S, Udompunturuk S, Kobkitjaroen J, et al. (2010) Multiple KIR gene polymorphisms are associated with plasma viral loads in SIV-infected rhesus macaques. Cell Immunol 263: 176-187.

21. Kruse PH, Rosner C, Walter L (2010) Characterization of rhesus macaque KIR genotypes and haplotypes. Immunogenetics 62: 281-293.

22. Degenhardt JD, de Candia P, Chabot A, Schwartz S, Henderson L, et al. (2009) Copy number variation of CCL3-like genes affects rate of progression to simianAIDS in Rhesus Macaques (Macaca mulatta). PLoS Genet 5: e1000346.

23. Yasutomi Y, Reimann KA, Lord CI, Miller MD, Letvin NL (1993) Simian immunodeficiency virus-specific CD8+ lymphocyte response in acutely infected rhesus monkeys. J Virol 67: 1707-1711.

24. Pal R, Venzon D, Letvin NL, Santra S, Montefiori DC, et al. (2002) ALVACSIV-gag-pol-env-based vaccination and macaque major histocompatibility complex class I $\left(\mathrm{A}^{*} 01\right)$ delay simian immunodeficiency virus SIVmac-induced immunodeficiency. J Virol 76: 292-302.

25. Mothe BR, Weinfurter J, Wang C, Rehrauer W, Wilson N, et al. (2003) Expression of the major histocompatibility complex class I molecule Mamu$\mathrm{A}^{* 01}$ is associated with control of simian immunodeficiency virus SIVmac239 replication. J Virol 77: 2736-2740.

26. Loffredo JT, Maxwell J, Qi Y, Glidden CE, Borchardt GJ, et al. (2007) MamuB*08-positive macaques control simian immunodeficiency virus replication. J Virol 81: 8827-8832

27. Yant LJ, Friedrich TC, Johnson RG, May GE, Maness NJ, et al. (2006) The high-frequency major histocompatibility complex class I allele Mamu-B*17 is associated with control of simian immunodeficiency virus SIVmac239 replication. J Virol 80: 5074-5077.

28. Lim SY, Rogers T, Chan T, Whitney JB, Kim J, et al. (2010) TRIM5alpha Modulates Immunodeficiency Virus Control in Rhesus Monkeys. PLoS Pathog 6: e1000738.

29. Lim SY, Chan T, Gelman RS, Whitney JB, O'Brien KL, et al. (2010) Contributions of Mamu-A*01 status and TRIM5 allele expression, but not 
CCL3L copy number variation, to the control of SIVmac251 replication in Indian-origin rhesus monkeys. PLoS Genet 6: e1000997.

30. Lifson JD, Nowak MA, Goldstein S, Rossio JL, Kinter A, et al. (1997) The extent of early viral replication is a critical determinant of the natural history of simian immunodeficiency virus infection. J Virol 71: 9508-9514.

31. Letvin NL, Mascola JR, Sun Y, Gorgone DA, Buzby AP, et al. (2006) Preserved $\mathrm{CD} 4+$ central memory $\mathrm{T}$ cells and survival in vaccinated SIV-challenged monkeys. Science 312: 1530-1533.

32. Valiante NM, Uhrberg M, Shilling HG, Lienert-Weidenbach K, Arnett KL, et al. (1997) Functionally and structurally distinct NK cell receptor repertoires in the peripheral blood of two human donors. Immunity 7: 739-751.

33. Bostik P, Kobkitjaroen J, Tang W, Villinger F, Pereira LE, et al. (2009) Decreased NK cell frequency and function is associated with increased risk of KIR3DL allele polymorphism in simian immunodeficiency virus-infected rhesus macaques with high viral loads. J Immunol 182: 3638-3649.

34. Reeves RK, Gillis J, Wong FE, Yu Y, Connole M, et al. (2010) CD16- natural killer cells: enrichment in mucosal and secondary lymphoid tissues and altered function during chronic SIV infection. Blood 115: 4439-4446.

35. Martin MP, Qi Y, Gao X, Yamada E, Martin JN, et al. (2007) Innate partnership of HLA-B and KIR3DL1 subtypes against HIV-1. Nat Genet 39: $733-740$.

36. Qi Y, Martin MP, Gao X, Jacobson L, Goedert JJ, et al. (2006) KIR/HLA pleiotropism: protection against both HIV and opportunistic infections. PLoS Pathog 2: e79.

37. Boulet S, Sharafi S, Simic N, Bruneau J, Routy JP, et al. (2008) Increased proportion of KIR3DS1 homozygotes in HIV-exposed uninfected individuals. Aids 22: 595-599.

38. Gaudieri S, DeSantis D, McKinnon E, Moore C, Nolan D, et al. (2005) Killer immunoglobulin-like receptors and HLA act both independently and synergistically to modify HIV disease progression. Genes Immun 6: 683-690.

39. Jennes W, Verheyden S, Demanet C, Adje-Toure CA, Vuylsteke B, et al. (2006) Cutting edge: resistance to HIV-1 infection among African female sex workers is associated with inhibitory KIR in the absence of their HLA ligands. J Immunol 177: 6588-6592.

40. Ravet S, Scott-Algara D, Bonnet E, Tran HK, Tran T, et al. (2007) Distinctive NK-cell receptor repertoires sustain high-level constitutive NK-cell activation in HIV-exposed uninfected individuals. Blood 109: 4296-4305.

41. Middleton D, Gonzalez A, Gilmore PM (2007) Studies on the expression of the deleted KIR2DS4*003 gene product and distribution of KIR2DS4 deleted and nondeleted versions in different populations. Hum Immunol 68: 128-134.
42. Goodridge JP, Lathbury LJ, Steiner NK, Shulse CN, Pullikotil P, et al. (2007) Three common alleles of KIR2DL4 (CD158d) encode constitutively expressed, inducible and secreted receptors in NK cells. Eur J Immunol 37: 199-211.

43. Sauermann U, Siddiqui R, Suh YS, Platzer M, Leuchte N, et al. (2008) Mhc class I haplotypes associated with survival time in simian immunodeficiency virus (SIV)-infected rhesus macaques. Genes Immun 9: 69-80.

44. Borrow P, Lewicki H, Hahn BH, Shaw GM, Oldstone MB (1994) Virus-specific CD8+ cytotoxic T-lymphocyte activity associated with control of viremia in primary human immunodeficiency virus type 1 infection. J Virol 68: 6103-6110.

45. Koup RA (1994) Virus escape from CTL recognition. J Exp Med 180: 779-782.

46. Matano T, Shibata R, Siemon C, Connors M, Lane HC, et al. (1998) Administration of an anti-CD8 monoclonal antibody interferes with the clearance of chimeric simian/human immunodeficiency virus during primary infections of rhesus macaques. J Virol 72: 164-169.

47. Jin X, Bauer DE, Tuttleton SE, Lewin S, Gettie A, et al. (1999) Dramatic rise in plasma viremia after CD8(+) T cell depletion in simian immunodeficiency virusinfected macaques. J Exp Med 189: 991-998.

48. Schmitz JE, Kuroda MJ, Santra S, Sasseville VG, Simon MA, et al. (1999) Control of viremia in simian immunodeficiency virus infection by CD8+ lymphocytes. Science 283: 857-860.

49. Mavilio D, Lombardo G, Kinter A, Fogli M, La Sala A, et al. (2006) Characterization of the defective interaction between a subset of natural killer cells and dendritic cells in HIV-1 infection. J Exp Med 203: 2339-2350.

50. Alter G, Teigen N, Davis BT, Addo MM, Suscovich TJ, et al. (2005) Sequential deregulation of NK cell subset distribution and function starting in acute HIV-1 infection. Blood 106: 3366-3369.

51. Mavilio D, Benjamin J, Daucher M, Lombardo G, Kottilil S, et al. (2003) Natural killer cells in HIV-1 infection: dichotomous effects of viremia on inhibitory and activating receptors and their functional correlates. Proc Natl Acad Sci U S A 100: 15011-15016.

52. Sun Y, Permar SR, Buzby AP, Letvin NL (2007) Memory CD4+ T-lymphocyte loss and dysfunction during primary simian immunodeficiency virus infection. J Virol 81: 8009-8015.

53. Kozlowski P, Lin M, Meikle L, Kwiatkowski DJ (2007) Robust method for distinguishing heterozygous from homozygous transgenic alleles by multiplex ligation-dependent probe assay. Biotechniques 42: 584, 586, 588.

54. Chenna R, Sugawara H, Koike T, Lopez R, Gibson TJ, et al. (2003) Multiple sequence alignment with the Clustal series of programs. Nucleic Acids Res 31: 3497-3500. 